\title{
КОМПЛЕКСНЫЙ РЕГИОНАРНЫЙ БОЛЕВОЙ СИНДРОМ - РЕГИОНАРНАЯ СКЕЛЕТНО-МЫШЕЧНАЯ БОЛЬ
}

\author{
*Иваничев Г.А. \\ Казанская Государственная Медииинская Академия, Казань
}

Комплексный регионарный болевой синдром руки (синдром Зудека) рассматривается как типовой патологический процесс, ведущим слагаемым которого является миофасциальный связочный болевой синдром ротаторов предплечья с ирритацией срединного нерва, содержащего большое количество симпатических волокон. 1 стадия - блокирование первого ребра с ирритацией звёздчатого узла и одновременное блокирование локтевого сустава с формированием миофасциального болевого синдрома в ротаторах предплечья. 2 стадия - регионарный миофасциальный синдром с ирритацией срединного нерва в верхней трети предплечья в фиброзно-мышечном канале. 3 стадия - завершение развития верхне-квадрантного вегетативно-ирритативного типичного комплексного регионарного болевого синдрома руки.

Ключевые слова: регинарная боль, миофасциальный болевой синдром.

$\mathrm{K}$ омплексный регионарный болевой синдром руки $[1,2,3,5,6,25,26]$, (синдром Зудека) представляет собоймучительные болезненныепереживания в одной руке, чаще в дистальных её отделах, в сочетании с чувствительными нарушениями (гипо- или анестезией, гиперпатией, аллодинией (восприятие любого раздражения как болевой), вегетативно-трофическими расстройствами (отеком, изменением окраски кожных покровов, локальным изменением кожной температуры, нарушением потоотделения, изменением скорости роста ногтей и волос, локальным остеопорозом, и расстройствами движений в форме негрубого пареза. Это комплекс ранее описывался под названием «рефлекторная симпатическая дистрофия» и «каузалгия» или синдром Зудека [5, 17, 18, 20, 21, 22, 24]. В последнее время установлено, что «симпатически поддерживаемая боль» имеет «симпатически независимую боль», что явилось поводом для нового термина «комплексный регионарный болевой синдром» (КРБС), предложенного в 1994 году Международной ассоциацией по изучению боли в классификации болевых синдромов. КРБС рассматривается в группе туннельных синдромов как проявления:
1) местной компрессии нервных стволов (срединного нерва) и связанной с ней ишемией, возникающей вследствие сужения миофасциальных каналов, через которые проходит срединный нерв, 2) вследствие местных процессов, увеличивающих объём периневральных тканей (травмы нервных стволов, гормонально-эндокринные и обменные нарушения, при физических перегрузках), ведущие к утолщению, отеку, разрыхлению окружающих нерв тканей. Развивается компрессионно-ишемическая невропатия (туннельная невропатия, ловушечная невропатия) [4, 16,27]. Подчёркивается роль миофасциальных триггерных пунктов этой зоны, ирритация которых может провоцировать и воспроизводить вегетативные и болевые реакции $[6,16,23]$. Релаксационные техники и миопунктура этой зоны могут купировать уплотнение и конфликт в туннельном канале. Критерием клинической диагностики туннельного сдавления являются симптомы, возникающие от поколачивания места предполагаемого сдавления парестезии, снижение рефлексов, слабость пальцев кисти. При отсутствии своевременного устранения «удавки» возможны гипестезии и атрофии.

*e-mail: ivanchev@mi.ru 
КРБС относится к разряду нечастых неврологических синдромов, хотя предшествующие и сопутствующие причинные факторы и условия его возникновения складываются очень часто. В этой связи, недостаточно изученным является роль спинальных (исполнительных) и церебральных (программных) продуктов в обеспечении деятельности локомоторной системы и вегетативного обеспечения движений руки.

Материал и методы. За время практической (более 40 лет) деятельности автора этой публикации в неврологической практике в условиях крупных неврологических клиник наблюдалось не более нескольких десятков больных с КРБС (в современной терминологии). В связи с изменившимся подходом в научной разработке проблем мышечной боли, в последние годы (2000-2011гг.) мы имели возможность целенаправленного анализа развития КРБС у 15 больных (12 женщин и 3 мужчин) в возрасте от 45-56 лет. У всех пациентов патологический процесс наблюдался слева, все они были правши. 12 пациентов курировались в стадии развёрнутых клинических проявлений, 3 - в стадии исхода заболевания.

Обследование включало стандартное неврологическое исследование и мануальную диагностику состояния аппарата движения. Инструментальное исследование включало регистрацию ЭМГ и вызванных потенциалов нервной системы (СБС, ССВП, МР, АСВП) по стандартной методике в динамике патологического процесса. Биопсийный материал не исследовался. Состояние вегетативного тонуса, вегетативной регуляции и вегетативного обеспечения деятельности оценивались клиническими и рутинными вегетативными тестами.

Результаты. Анамнез - (Сводная характеристика). Обращает внимание значительный перечень «лёгких» травм верхних конечностей - падение на плечо, вытянутую руку, рывковое «хватание» окружающих предметов при потере равновесия, или жёсткий резкий упор на кисть и др. У 2 пациентов был перелом костей предплечья (лучевой кости), 1
- ножевое ранение тканей предплечья. У всех больных боль в шейно-грудном переходе, особенно на стороне поражённой конечности. Начало заболевания для всех больных «медленное», в течение 4-6 недель, пациенты с перенесенным переломом костей предплечья устанавливали «естественные» быстрые причинно-следственные отношения. В динамике симптомов примечательным является нарастание болезненности в руке от проксимального отдела в дистальном направлении, раннее ограничение отведения и наружной ротации предплечья. В дальнейшем присоединяется жгучий характер боли (5-8 месяцев). В течение 8-10 месяцев определяются характерные трофические расстройства. Максимальная продолжительность наблюдения - 6 лет. Исходы заболевания: 1) Инвалидность в связи с потерей трудоспособности - 4 человека со стажем заболевания более 3 лет. 2) Выздоровление - у всех 12 больных, наблюдавшихся нами лично за последних 2 года.

Сводная характеристика клинических проявлений. Болевой синдром - ощущения жжения, ноющие или ломящие боли в сочетании с чувствительными нарушениями (гипо- или анестезией, гиперпатией, аллодинией, т.е. восприятием стимуляции любой модальности). Болевой сидром может иметь две основные характеристики: жгучая боль - ощущается в виде жжения, чаще поверхностная, от средней до высокой степени интенсивности, четко описывается пациентом; ноющая боль - ноющего, ломящего, тянущего характера, чаще ощущается, как глубинная, имеет средний или ниже среднего уровень интенсивности, пациенты не могут дать eе четкого описания. Эти два типа боли различаются по своей длительности: жгучие боли в трети случаев сохраняются более 6 месяцев, иногдатрансформируются в ноющие; первично ноющие боли после 6 месяцев от начала заболевания не отмечены. Более чем 3/4 пациентов имеют спонтанные постоянные боли. Боль нередко следует сразу за травмой, которая обычно не связана со значительным повреждением нерва. Она может наблюдаться вслед за переломом костей, мягким тканевым 
повреждением или иммобилизацией. Боль возникает обычно в течение первого месяца после воздействия провоцирующего фактора.

Вегетативно-трофические расстройства - отёк, цианоз кожных покровов, локальные изменения кожной температуры, гипергидроз, ускоренный рост ногтей и волос, локальный остеопороз. Выделены два основных комплекса вегетативно-трофических нарушений: 1) багровая или красная окраска кожи, отек, гипертермия, гипергидроз, ускорен рост ногтей, может быть ускорен рост волос, контрактура не выявлена; 2) окраска кожи белая или синюшная, гипотермия, гипо- или ангидроз, гипотрофия мягких тканей, дисхромия кожных покровов, замедлен рост ногтей и волос, контрактура у 7 больных. Первый комплекс встречается при длительности заболевания до 6 месяцев у 3/4 наблюдений, второй может развиться как в ранние, так и в поздние сроки. На рентгеногаммах - пятнистый остеопороз, выявляемый обычно на 3-4-й неделе от начала заболевания - у 8 больных, у 2 больных диффузный остеопороз.

Расстройства движений в форме различной степени ограничения движения в плече, пальцев кисти и дистального пареза у - всех больных.

Эмоционально-депрессивныерасстройства и ипохондрическое развитие личности - у 9 больных.

Особенным в наших наблюдениях мы считаем:

1. Сужение реберно-ключичного пространства.

2. Ирритация звёздчатого узла - у всех

3. Внутренний эпикондилит - 7

4. МФБС сгибателей кисти и пальцев - у Bcex

5. МФБС ротаторов предплечья, грубее

круглых пронаторов - у всех
6. Функциональное грубое блокирование (блокада) цервико-торакального перехода (С7-Т1) и 1 ребра - у всех

7. Функциональное блокирование локтевого сустава - у всех

8. Ретракция фиброзной пластины - у всех

9. Тревожно-ипохондрическое развитие личности - у всех.

Данные дополнительных методов исследования.

\section{Электромиография.}

Электромиографическая активность круглого пронатора и супинатора характеризуется теми параметрами, которые были отмечены нами $[7,15]$ ранее, подробное перечисление которых не входит в задачи этой публикации. Отметим основные:

1.

Электрофизиологическое «беспокойство» покоя, особенно на границе здорового и «больного» участков при регистрации накожными электродами.

2. Угнетение вплоть до полного отсутствия ЭМГ - активности центра мышечного гипертонуса при регистрации игольчатыми электродами.

3. Выраженная полифазия ПДДЕ В гипертонусе. В центре гипертонуса длительность ПДДЕ значительно уменьшена. Награнице с нормальной мышцей выявляются удлиненные и укороченные потенциалы действия, характерные первичномышечным заболеваниям (миодистрофиям).

4. Резкий прирост при растяжении мышцы ЭМГ активности переходного участка (стыка) между нормальной мышцей и гипертонусом.

Дляклиническойоценкифункционального резерва мускулатуры предплечья проводилась ритмическая динамическая проба. Суть пробы заключается в измерении времени, затраченного на выполнение 20 пронаторносупинаторных движений (циклов) в локтевом суставе в максимальном темпе (Таблица 1).

Таблица 1. Время, необходимое для выполнения ритмической динамической нагрузки вращателей предплечья.

\begin{tabular}{|l|l|}
\hline Группы испытуемых & Время (сек) \\
\hline Контроль (20) & $13,4 \pm 1,6$ \\
Начальный этап болезни & $21,5 \pm 2,4$ \\
Развернутая стадия заболевания & Более 1 минуты, отказы выполнения задания \\
\hline
\end{tabular}


Начало пробы

A
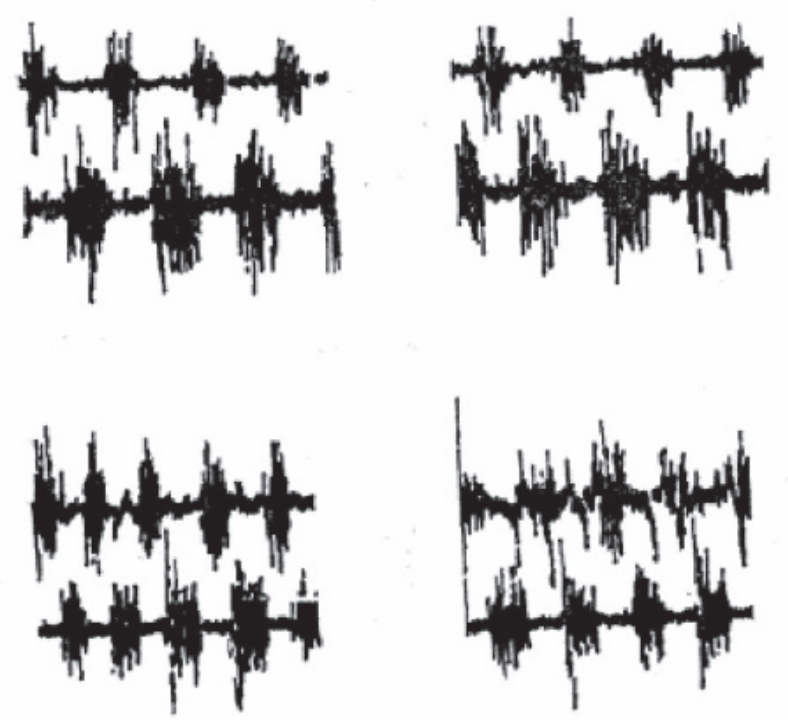

Б

1 сек

Рис. 1. Электромиография пронаторов (верхняя кривая) и супинаторов (нижняя кривая) предплечья при выполнении ритмической динамической нагрузки. А норма. Б - КРБС.

Выявляется грубое нарушение реципрокных отношений между пронаторами и супинаторами предплечья. Аналогичная ЭМГ картина между группами мышц, осуществляющих сгибание и разгибание кисти.

Скорость проведения моторного импульса по срединному илоктевым нервамдостоверно не изменена в сравнении создоровой стороной. Однако моторный импульс, регистрируемый с мышц тенара, распадается на несколько ответов с меньшей амплитудой. Это является свидетельством частичного поражения нерва вследствие туннельного сжатия срединного нерва в проксимальном отделе.

Рефлекторная активность ствола мозга. Методика регистрации мигательного рефлекса и анализ его позднего полисинаптического компонента являются эффективными в оценке рефлекторной активности ствола мозга. Методика оказалась адекватной и демонстративной в оценке выраженности клинических проявлений и динамики лечения больных МФБС.

При электрической стимуляции надбровья в проекции выхода надглазничного нерва вызывала в круговых мышцах глаза рефлекторные разряды, состоящие из двух компонентов: раннего(R1), дисинаптического, и позднего (R2), являющегося по своим характеристикам полисинаптическим [cм. наши ранние публикации - 7, 8, 15].
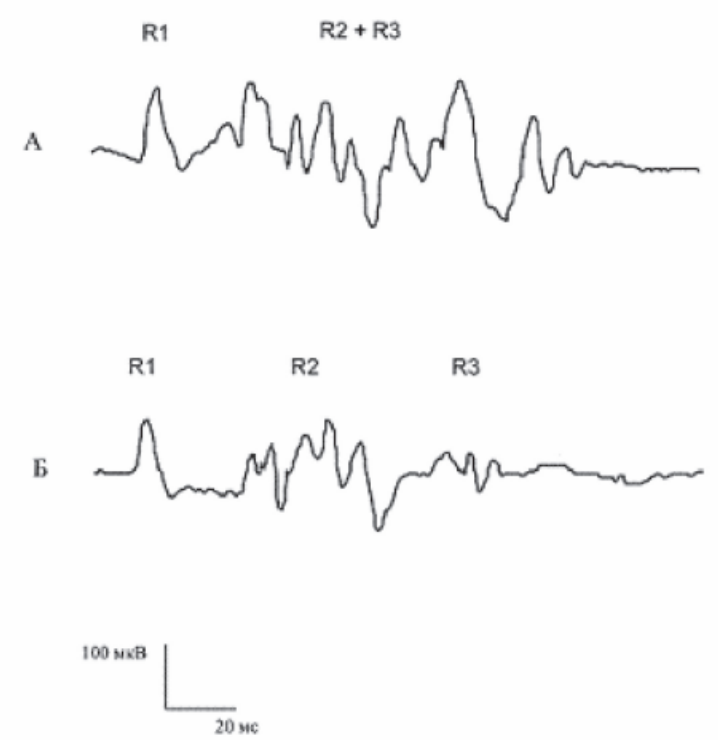

Рис. 2. Мигательный рефлекс:

А-гипервозбудимый тип рефлекторного ответа при КРБС. Б - норма.

Результаты проведенных исследований по изучению параметров мигательного рефлекса показали, что у больных МФБС наблюдаются разнонаправленные изменения рефлекторной возбудимости ствола мозга. Это позволило выделить три клиниконейрофизиологических варианта МФБС и подразделить всех исследуемых нами больных на три группы - «низкая полисинаптическая рефлекторная возбудимость», «нормальная полисинаптическая рефлекторная возбудимость» и «высокая полисинаптическая рефлекторная возбудимость у всех больных с КРБС выявляется очень высокая рефлекторная активность ствола мозга, проявляющаяся гипервозбудимым типом 
мигательного рефлекса. Следуетподчеркнуть, что ожидаемая асимметрия в рефлекторной возбудимости ствола мозга в регистрации раннего и поздних компонентов мигательного рефлекса не выявлена.

Соматосенсорные вызванные потенциалы (ССВП).Избирательнаяактивациягенераторов патологически усиленного возбуждения вследствие исходной слабости тормозных процессов при электрической стимуляции периферических нервов является адекватным методом изучения особенностей перцепции сенсорного потока из очага хронической боли. Для этого изучены параметры компонентов ССВП дальнего и ближнего поля у больных КРБС до и после лечения. Особое внимание уделялось изменениям латентностей компонентов ССВП в связи с тем, что уменьшение последней рассматривается как признак сенситизации нейронных цепей с формированием положительных обратных связей, преобразующих физиологическую функциональную алгическую систему в патологическую. Патофизиологической основой этого преобразования является ГПУВ $[7,9,10]$.

ССВП регистрировались в точках соматосенсорных проекций электрической стимуляции контралатерального срединного нерва в области запястья на стороне поражённой руки. Контроль - здоровая сторона. Активные и референтные электроды располагались по общепринятой стандартной схеме для регистрации соматосенсорных вызванных потенциалов срединного нерва. Нижняя полоса пропускания составляла 5,3 Гц, верхняя - 15 кГц. Эпоха анализа: 1) для ранних компонентов ССВП - 50 мс; 2) для промежуточных - 200 мс; 3) для поздних 500 мс. Это соответствовало делению ССВПна группы ранних (20-80мс), промежуточных (80$200 \mathrm{Mc})$ и поздних (200-400мс) компонентов. В каждой группе усреднялись 130 ответов.

Статистическое сравнение значений латентностей и амплитуд компонентов ССВП проводилось до и после лечения, а также с контрольной группой здоровых добровольцев (банк данных кафедры неврологии и рефлексотерапии). Были использованы критерий

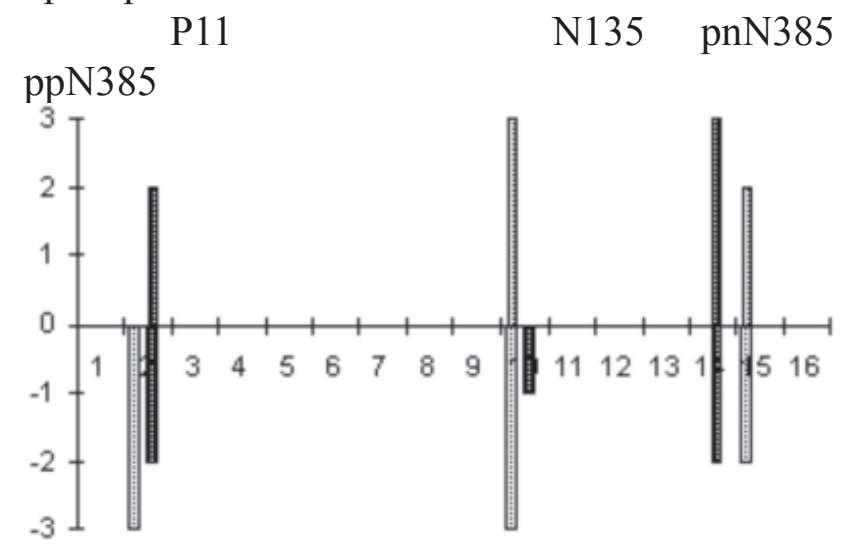

A

P9 P11 P45 N62 N135 pnP230 P230

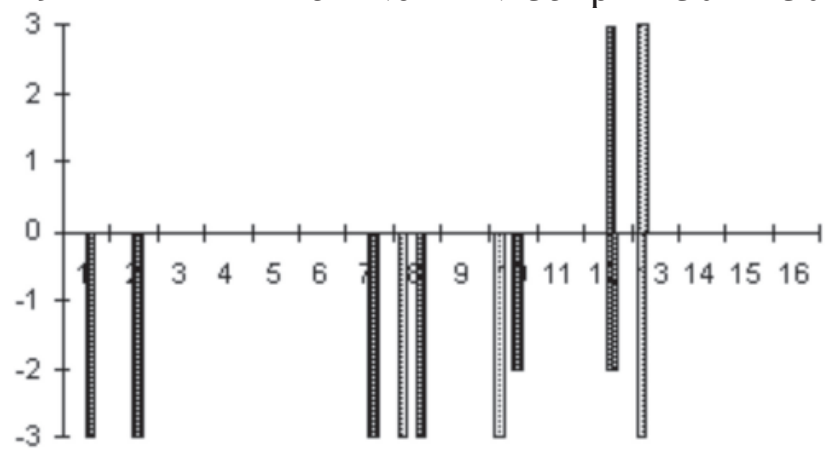

Б

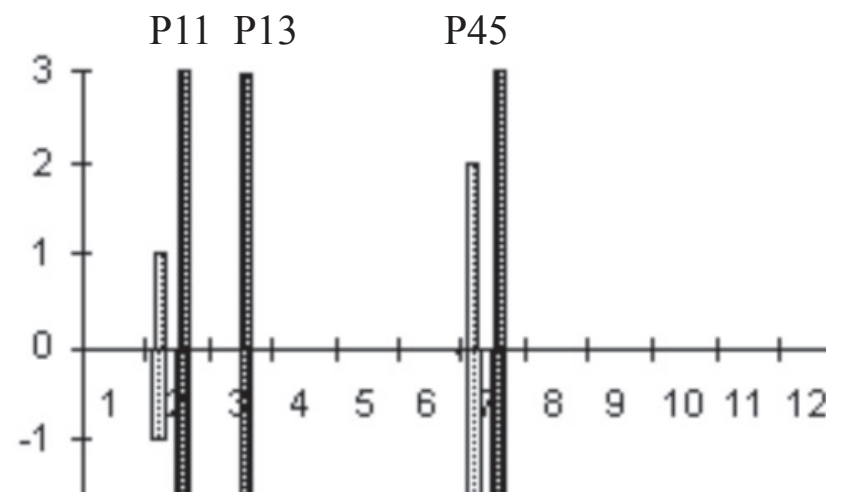

$\mathrm{B}$

Рис 3. Динамика модификации вызванной активности мозга в процессе купирования болевого синдрома при КРБС. А выраженный болевой синдром, Б- умеренный, В - легкий. По оси абсцисс в порядке возрастания представлены компоненты ВП дальнего и ближнего поля, по оси ординат - критерии Стьюдента. Положительные значения столбцов соответствуют амплитуде, отрицательные - латентности компонентов ВП (по сравнению с нормой). Светлые столбцы - до, темные - после лечения. 
Стьюдента для зависимых и независимых пар значений, критерий Уилкоксона для связанных и несвязанных совокупностей. При сравнении показателей по критерию Стьюдента выявлялись следующие степени различий латентностей и амплитуд: $\mathrm{P}<0,001$ - высокозначимые различия, $\mathrm{P}<0,05$ значимые различия, P11 P13 $\mathrm{P} 45 \mathrm{P}<0,09$ - слабозначимые. Было целесообразно оценивать их динамику с изображением соответствующих графических зависимостей не по численным значениям указанных характеристик, а на основании показателей различий. Это позволило в пределах одной гистограммы выявить тенденции изменений ССВП. Для этого были выбраны четыре степени различий, где первый показатель соответствует латентности, второй амплитуде:

Положительные значения указывают на тенденцию латентности или амплитуды до или после лечения к увеличению, отрицательные — к снижению (рис.3.)

Таким образом,привыраженныхиумеренно выраженных клинических проявлениях после лечения активный генератор смещается каудально, т.е. происходит как бы “сдвиг назад” системообразующей патологической альгической системы в область ранее существовавшего первичного генератора $[13,14]$.

У больных с легкой степенью клинических проявлений (что бывает в начале заболевания) и после лечения, напротив, выявляются более активные генераторные структуры, чем до лечения (уменьшение латентностей ранних и промежуточных компонентов ССВП). Это может означать, что после купирования болевого синдрома и устранения активных триггерных пунктов в ЦНС сохраняются латентные генераторы, смещающиеся каудально. Их активность не исчезает даже при полном субъективном выздоровлении и устранении латентных МФТП. Это имеет принципиальное значение в понимании механизмовхронизации и рецидива КРБС при самых разнообразных провоцирующих факторах - стрессовых ситуациях, переохлаждении, интоксикации и др. Другими словами, восстановление и хронизация патологической детерминантной системы происходит по механизму “второго удара" за счет возобновления активности латентных не только периферических мышечных, но и центральных (включая корковые) генераторов. Утверждение, что “патологическая детерминанта умирает последней и оживает первой” $[10,11]$ находит свое отражение в клинических проявлениях КРБС.

Имеется четкая латерализация вызванной активности мозга - установленная динамика ССВП проявляется только справа - (под нашим наблюдением находились больные только левосторонним КРБС).

Полисинаптические длинно- и короткопетлевые рефлекторные ответы (СБС - рефлексы). Для изучения супраспинальных механизмов ноцицептивногои антиноцицептивного реагирования была использована методика регистрации длиннопетлевых рефлекторных ответов и короткопетлевых вызванных потенциалов мигательного рефлекса [15].

Выбор исследования СБС-рефлекса в клинике КРБС произведён исходя из положения о возможном изменении генеза рефлекторных комплексов в рамках сенсомоторной системы, ответственной за генерализацию патологической алгической системы с участием миогенного триггерного пункта.

Регистрация СБС-рефлексов проводилась параллельно с регистрацией АСВП, ответы обоих видов вызванных ответов конвергируют в среднем мозге, что дало возможность проводить более полный анализ функциональных изменений ствола мозга в клинике КРБС.

СБС-рефлекс мышц шеи и плечевого пояса вызывался раздражением локтевого нерва в локтевой борозде с регистрацией ответа в дельтовидной, большой грудной, трапециевидной и плечелучевой мышцах.

Вычислялисреднийпоказательлатентности и длительности отдельно для первого и второго 
компонентов СБС-активности для каждой мышцы как у больных, так у здоровых лиц (контроль).

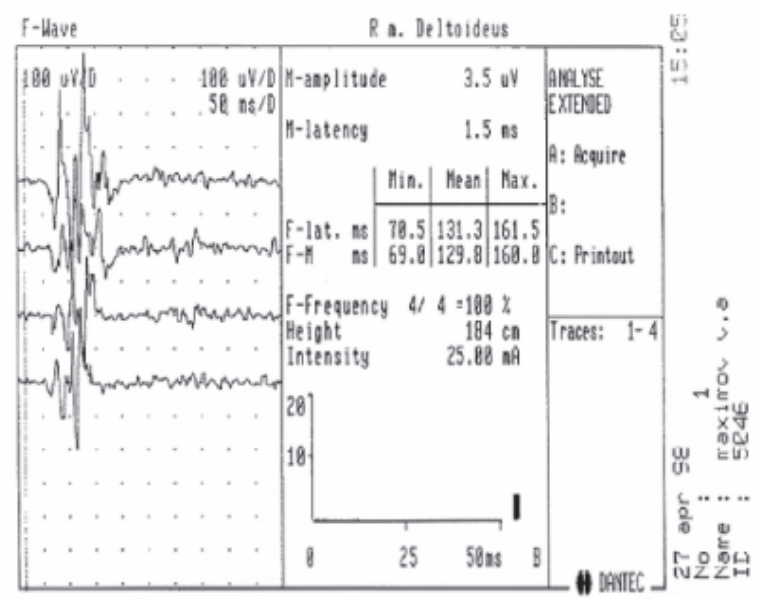

Рис. 4. СБС дельтовидной мышцы при КРБС.

Особенность

СБС-рефлекторной активности у больных с КРБС заключалась в низком пороге возникновения ответов, увеличении амплитуды, выраженной экспрессии ответов, что соответствует гиперрефлекторному варианту реагирования ствола мозга. Высокая активность оральных ствола мозга является свидетельством его готовности в реализации разнообразных полисинаптических рефлекторных ответов как соматического ряда, так и вегетативного обеспечения деятельности.

Акустические стволовые вызванные потенциалы (АСВП). В настоящем разделе работы показаны только результаты исследования АСВП у больных с КРБС. Исследования АСВП проведены до и после процедуры пунктурной аналгезии миофасциального триггерного пункта круглого пронатора и плече-лучевой мышцы на поражённой стороне [15].

Для лучшей идентификации компонентов АСВП проводили сопоставление записей при ипсилатеральной и контралатеральной регистрации. Выделяют пять основных пиков АСВП, отражающих активность слухового нерва (I), нижней оливы (II), трапециевидного тела (III), латеральной петли (IV) и нижнего двухолмия (V).

Идея исследования состояла в том, чтобы зарегистрироватьубольныхсКРБС вызванные ответы в исходном состоянии и после миофасциопунктуры, сопровождавшейся выраженным терапевтическим эффектом анальгезией.

Сравнение показателей амплитуд акустических стволовых вызванных потенциалов в исходном состоянии и при купировании болевого синдрома выявило увеличение первого и увеличение пятого компонентов.

\begin{tabular}{|c|c|}
\hline E & Testome 1 \\
\hline
\end{tabular}

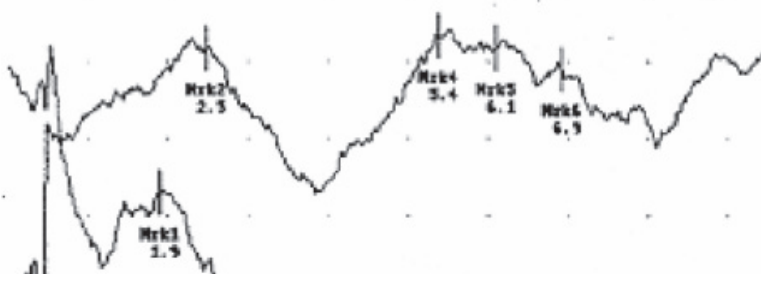

Рис. 5. АСВП на стороне поражения при КРБС.

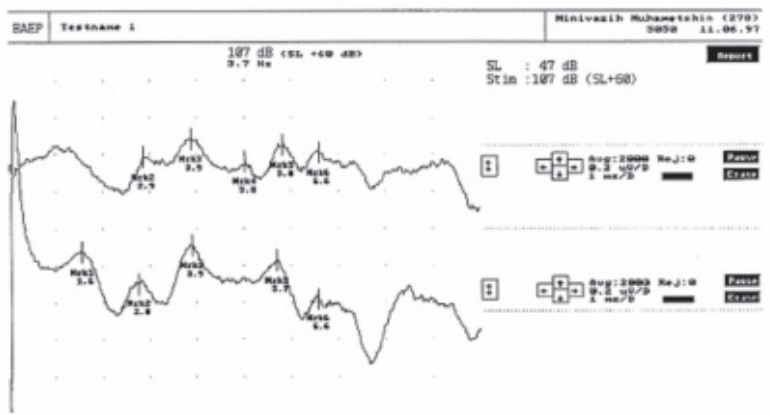

Рис. 6. АСВП после миопунктуры триггерного пункта в круглом пронаторе.

Качественными отличиями при миопунктуре в безболезненный участок служили изменения II и III пиков. Иные изменения наблюдались при воздействии на триггерный пункт: увеличение I и V компонентов со стороны стимуляции. 
Последующие изменения II пика при повышении активности I отсутствуют, что несколько противоречит закономерностям проведения акустического сигнала. Объяснение последнему факту заключается в признании существовании других путей, которые параллельно и независимо проводят потоки информации высокого биологического значения. Часть потока тормозится на более низких уровнях - поэтому нет стволовых усилений пиков. Часть потока непосредственнодоставляется в таламические ядра - для обеспечения антиноцицептивных функций в условиях болевой импульсации. Неноцицептивный информационный поток вызывает дестабилизацию только стволового уровня, без участия главного интегратора сенсорных систем - таламуса.

Полученные данные свидетельствуют о существенном влиянии миофасциопунктуры нафункциональноесостояниестволамозга, что является прямым доказательством изменения активности антиноцицептивной системы ствола под влиянием гиперстимуляционной акупунктуры - миофасциотомии. Ранее нами было показано, что под влиянием МФТП формируются мигрирующие по вертикальной оси ЦНС генераторы патологически усиленного возбуждения с разной активностью, клинически проявляющиеся обострением или ремиссией МФБС.

Таким образом, регистрируемые афферентные ответы с малой латентностью являются свидетельством значительной дисфункции каудальных отделов ствола мозга при КРБС.

Моносинаптические спинальные рефлексы (H - ответ). Параметры Н-рефлекса можно использовать в качестве интегративного теста, отражающего функциональное состояние спинальных структур в условиях интенсивного потока периферической ноцицептивной афферентации.

$\mathrm{H}$ - рефлекс является эквивалентом ахиллова рефлекса и в норме у взрослых определяется в мышцах голени (икроножной и камбаловидной) при стимуляции большеберцового нерва в подколенной ямке.
При постепенном увеличении интенсивности раздражения вначале появляется Н-рефлекс, при дальнейшем нарастании силы раздражения наряду с ростом амплитуды Н-рефлекса определяется появление М-ответа, который является прямым мышечным ответом на электрическую стимуляцию нерва. По мере все большего роста М-ответа амплитуда Н-рефлекса начинает снижаться вплоть до полного угнетения. При анализе оцениваются пороги, латентные периоды, максимальные амплитуды Н-рефлекса и М-ответа. В качестве основного показателя, характеризующегофункциональноесостояние сегментарного аппарата, используется отношение максимальной амплитуды Н-рефлекса к максимальной амплитуде М-ответа, выраженное в процентах. Это величина позволяет судить о том, какая часть мотонейронного пула мышцы возбуждается стимуляцией волокон типа Іа. В норме она составляет $40-60 \%$.

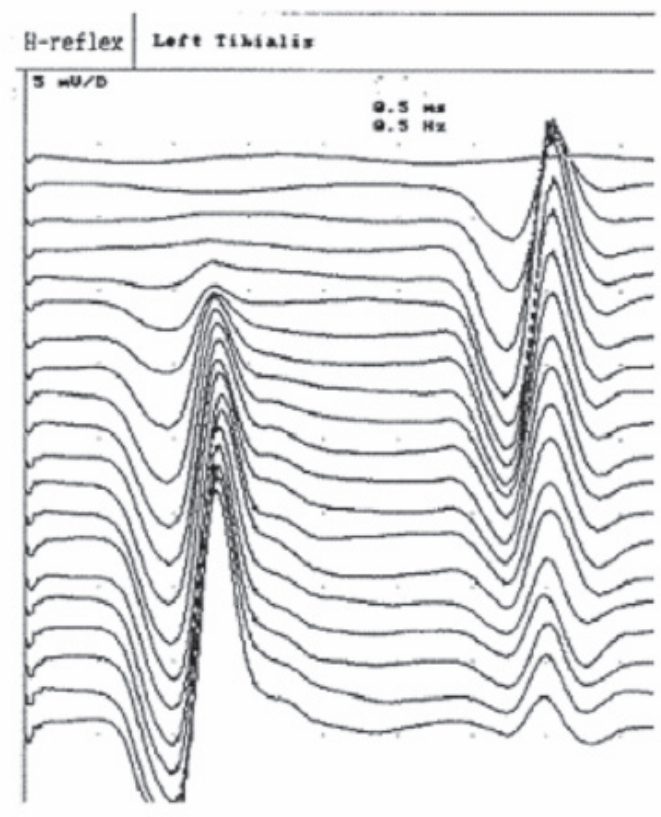

М-ответ Н-рефлекс

Рис. 7. Н-рефлекс икроножной мышцы при КРБС - повышение рефлекторной возбудимости.

Определяетсязначительное расторможение супраспинальных образований, что является 
характерным для многих патологических состояний, включая болевое реагирование.

Ноцицептивныйфлексорный рефлекс (НФР).

Ноцицептивный флексорный рефлекс позволяет определять состояние ноцицептивных иантиноцицептивных систем, а также изучать роль и влияние различных медиаторов, вовлеченных в контроль боли. Кроме того, он может быть использован для изучения патофизиологии различных клинических синдромов, характеризующихся хронической болью или измененной болевой перцепцией.

НФР является классическим сгибательным рефлексом, вызываемым с короткой головки двуглавой мышцы бедра при электрической стимуляции икроножного нерва.

Сгибательные рефлексы защитного типа при стимуляции икроножного нерва представляют собой четко дифференцированные, мощныерефлекторные ответы, имеющие два последовательных компонента: RII и RIII. Латентность RII ответа малая - 40-70 мс. Этот ответ можно получить только при неболевой стимуляции, воспринимаемой как легкое покалывание. Латентность RIII ответа больше: 90-130 мс и его появление связано с локальным болевым ощущением в месте стимуляции. Ответ RII появляется обычно первым, при последующем увеличении силы тока появляется ответ RIII (Рис. 8).
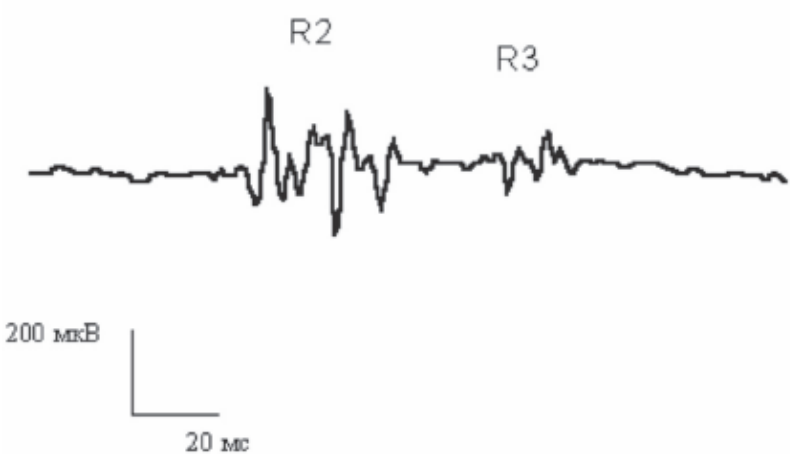

Рис.8. Ноцицептивный флексорный рефлекс: - аналог СБС - рефлекса.

Ноцицептивный рефлекс по уровню замыкания являются спино-бульбо- спинальным. Его R2 компонент реализуется интернейронными сетями на спинальном уровне, R3 компонент замыкается через ретикулярную формацию ствола мозга при этом в основном вовлекается высокопороговое ноцицептивное гигантоклеточное ядро.

На основании исследования НФР складывается единственное в нашем случае заключение - порог болевого реагирования снижен.

Лечение. В нашу задачу не входит обзор существующих методик лечения. В этой части публикации отметим особенности применённой нами схемы лечения.

1. Устранение миофасциального туннельного механизма за счёт применения мягких техник манаульной терапии и пунктурной аналгезии.

2. Мобилизация блокированного 1 ребра на стороне КРБС, шейно-грудного перехода и локтевого суставов.

3. Снижение местной ирритативной активности срединного нерва - устранение гипералгезии и каузальгического компонента местными анестетиками и рефлексотерапией. Всем больным проводились вагосимпатические блокады по классической методике.

4. Антиконвульсанты для купирования механизмов невропатической боли.

5. Антидепрессанты - по показаниям.

Обсуждение. Таким образом, цепь событий в механизмах развития КРБС позволяет определить общую ситуацию как преобладание ирритативных процессов наддефицитарными. Начальное звено цепи - функциональное блокирование («заклинивание», «блокада») щейно-грудного перехода C7 - T1, что может быть результатом прямой травмы, заболеваний шейного отдела позвоночника, аномального высокого ребра и др. Блокирование шейно-грудного отдела - ключевого отдела позвоночника, как и кранио-вертебрального перехода, является стартовой для многих патологических процессов. Инициальный фактор может быть реализован как типовой патологический 
процесс только при ряде условий: 1) Сочетанное блокирование первого ребра и локтевого сустава; 2) Ирритация (ганглионит) звёздчатого узла, 3) Исходная вегетативная недостаточность (первичный СВД), 4) Тревожно-мнительный тип личности.

Следует отметить, что эти условия патогенеза КРБС являются существенными. Очевидно, что в течение жизни человек имеет немало эпизодов травматического характера, профессиональных перегрузок, болей в шее. Однако, запуск и развитие КРБС происходит довольно редко. Случайнозакономерная констелляция причин и условий обсуждаемого синдрома фатально определяют последующую историю событий. Сказанное справедливо и в отношении ряда других болезненных синдромов руки (плече-лопаточногопериартроза, синдрома Стейнброкера и др.).

Клиническая картина КРБС складывается как этапный процесс. С учётом литературных данных и личного опыта цепь событий представляется в следующем виде событий.

Начальный этап - формирование очага боли в проксимальном отделе руки. В очаге активным субстратом является скелетномышечная боль вследствие блокированного шейно-грудного перехода, односторонней блокады первого ребра и ключичноакромиального сустава с сопровождающими их мышечно-тоническими реакциями паравертебральной мускулатуры и плечевого пояса. Патогенетическое значение имеет миофасциальная боль верхней порции трапециевидной, лестничных иподключичной мышцы в условиях узкого ключичнорёберного промежутка. Необходимый компонент - ирритация звёздчатого узла, расположенного на шейке блокированного первого ребра - верхнеквадрантный вегетативно-ирритативный синдром.

Расширение зоны патологического очага возможно только при наличии следующего фактора, являющего основным, адресата местного процесса (осаждающего фактора). Это болезненное блокирование локтевого сустава с обязательными элементами этой фатальной ситуации. Решающей в этой ситуации является нарушение реципрокных отношений между пронаторами и супинаторами предплечья. Ситуация же заключается в формировании на локте жгута из мышечно-связочного комплекса своего сустава. Активные элементы этой перетяжки - супинаторы и пронаторы предплечья, являющиеся антагонистами по существу этой важнейшей функции, становятся реципрокно несостоятельными. Это означает, что под влиянием болевой афферентации попеременноевыключение мышц-вращателей предплечья не происходит - обе групп мышц находятся в состоянии напряжения, когда в этом нет необходимости. Поперечная перетяжка в последующем подкрепляется укорочением фиброзной пластины. Тем самым заканчивается формирование типичного туннельного синдрома. Это миофасциальный болевой синдром локтевого сустава поперечной локализации.

Как известно, супинационнопронационные движения осуществляются вокруг диагональной оси, проходящей проксимально через головку лучевой кости, дистально - через головку локтевой. Антагонистами этих движений являются напряжение соответствующей группы мышц и связок. При супинации тормозящее влияние оказывают пронаторы и передний отдел капсулы, при пронации, наоборот, супинаторы. Плечевая мышца (m. brachialis) представлена главным сгибателем, a трехглавая (m. tricepsbrachii) - главным разгибателем. Функцию главного супинатора выполняет двуглавая мышца плеча (m. bicepsbrachii) в сочетании мышцей одноимённым названием, а истинным его антагонистом является круглый пронатор (m. pronatorteres). Исходная повышенная контрактильная активность сгибателей и пронаторов в условиях болевой активации тонуса этих же мышц способствует развёртыванию туннельного синдрома, основным участником которого является срединный нерв и плечевая артерия (синдром круглого пронатора, Тинеля, синдром ленты Стразера, Кулона, Лорда и 
Бедосье, супракондилярного отростка).

Итоговый процесс - завершение формирования типичной картины КРБС. Нарастающая дисфункция стволовых образований мозга подвлиянием интенсивной боли способствуетзавершению изакреплению синдрома вегетативной дисфункции, ослабления активности антиноцицептивной системы и программного уровня «В» $[7,9]$. Формирование патологической алгической системы $[10,11]$, в структуре которой в патогенетической связи оказываются двигательная система с дефектным продуктом исполнения движения (мышечно-связочный гипертонус и заблокированные суставы) и нарастающая дисфункция вегетативного обеспечения означаетзавершениеобразования порочного кольца «дефект программы движения - дефект исполнения движения». Положительная обратная связь, поощряющая развитие предыдущих патологических продуктов деятельности программы в последующие продукты [10], перестраивает внутреннюю структуру физиологической функциональной системы организации движения в патологическую комплексную систему - в нашем варианте как комплексный регионарный болевой синдром.

Заключение. Комплексный регионарный болевой синдром руки (синдром Зудека) представляет собой типовой патологический процесс, ведущим слагаемым которого является миофасциальный и связочный болевой синдром ротаторов предплечья с ирритацией срединного нерва, содержащего большое количество симпатических волокон. Патологическая алгическая система, в структуре которой в патогенетической связи оказываются двигательная система с дефектным продуктом исполнения движения (мышечно-связочный гипертонус и заблокированные суставы) и нарастающая дисфункция вегетативного обеспечения движения, представляет собой завершенное порочное кольцо «дефект программы движения - дефект исполнения движения». Начальная стадия патологического процесса - блокирование первого ребра с ирритацией звёздчатого узла и одновременное блокирование локтевого сустава с формированием миофасциального болевого синдрома в ротаторах предплечья. В последующем регионарный миофасциальныйболевой синдром с ирритацией срединного нерва в верхней трети предплечья в фиброзно-мышечном канале поддерживает нарастающую дисфункцию центральных вегетативных образований и уровня синергий «В» активной программы даижений по Бернштейну. Завершение формирования устойчивой патологической системы со многими её участникамизнаменует верхнеквадрантный вегетативно-ирритативный типичный комплексный регионарный болевой синдром руки.

\section{ЛИТЕРАТУРА}

1. Астапенко М.Г., Эрялис П.С. Внесуставные заболевания мягких тканей опорно-двигательного аппарата, с. 124, М., 1975;

2. Бурьянов А.А. Посттравматическая дистрофия конечностей (синдром Зудека). Вопросы патогенеза, диагностики и лечения: Автореф. дисс. канд. мед.наук.-Харьков, 1990.- 24 с.

3. Витюгов И.А., Котенко В.В. Синдром Зудека как общемедицинская проблема//Ортопед., травматол.- 1977.- N 11. - С.86-89.

4. Жулёв Н.М. ,Жулев С,Н., Лалаян Т.В., Осетров Б.А. Невропатии. Руководство для врачей. 2005,
$416 \mathrm{c}$

5. Котенко В.В., Ланшаков В.А. Посттравматическая дистрофия руки. - М.: Медицина, 1987. - 128 с.

6. Левина Р.Е., Кипервас И.П. и Будунова Л.В. Опыт лечения больных синдромом Зудека в условиях амбулаторного отделения восстановительного лечения, Вопр. курортол., физиотер., №6, с. 67, 1989.

7. Иваничев Г. А. Мануальная медицина. М: МедПресс 1998.

8. Иваничев Г. А. Сенсорное взаимодействие в 
механизмах акупунктуры. Казань 1999,145 с.

9. Иваничев Г. А. Миофасциальная боль. Казань $2007,390 \mathrm{c}$.

10. Крыжановский Г. Н. Детерминантные структуры в патологии нервной системы. М: Медицина 1980.

11. Крыжановский Г. Н. Общая патофизиология нервной системы. М: Медицина 1997.

12. Лиманский Ю. П. Интегративные механизмы ствола головного мозга. Л: Наука 1983; 61-111.

13. Овчинников А. В. Особенности модификации детерминантных структур патологических алгических систем в процессе купирования миофасциального болевого синдрома. Патологическая боль: Тезисы доклада Российской научной конференции 14-16 октября 1999. Новосибирск 1999; 7-8.

14. Овчинников А. В. Соматосенсорные вызванные потенциалы и их взаимосвязь с миофасциальными триггерными пунктами при миофасциальных болевых синдромах. Боль и паллиативная помощь: Тезисы докладов Сибирской Межрегиональной научно-практической конференции 10-12 сентября 2002. Новосибирск 2002; 95-96.

15. Старосельцева Н.Г. Функциональное состояние супрасегментарных структур мозга при миофасциальном болевом синдроме.-Автореф. дисс.кандюмед.наукю-Казань, 1998.-28сю

16. Тревелл Дж. Г., Симонс Д. Г. Миофасциальные боли: Пер. с англ. М: Медицина 1989; 130-145.

17. Amadio P.C., Mackinnon S., Merrit W.H., Brody G.S., Terzis J.K. Reflex sympathetic dystrophy syndrome: Consensus report of an ad hoc committee of the American Association forand Surgery on the definition of reflex sympathetic dystrophy syndrome //Plast. Reconst. Surg. 1991. - V. 87, № 2. - P. 371375.

18. 5. Evans J.A.: Reflex sympathetic dystrophy. Surg. Gynecol. Obstet. 82:36, 1946.

19. Field S., Warwick D., Bannister G. Features of algodystrophy after Colles' fracture //J. Hand Surg.- 1992.- V.17B, N3.- P.318-320.

20. 17 .Geertzen J.H.B., Bruijh H., Bruijn-Kofman A.T., Arendzen J.H. Reflex sympathetic dystrophy: early treatment and psychological aspects //Arch. Phys.Med.Rehab.- 1994.- V.75, N4.-P.442- 447.

21. Kline S.C., Holder L.E. Segmental reflex sympathetic dystrophy: clinical and scintigraphic criteria //J.Hand Surg.- 1993.- V.18A, N5.- P.853-859.

22. Kozin F. et al. The reflex sympathetic dystrophy syndrome. I. Clinical and histological studies; Evidence for bilaterality, response to corticosteroids and articular involvement. Am. J. Med. 60;321, 1976.

23. Mitchell S.W., Moorehouse G.R., Keen W.W.: Gunshot Wounds and Other Injuries of Nerves. Philadelphia, J.B. Lippincott, 1864.

24. Pollock F.E., Koman L.A., Smith B.P., Poehling G.G. Patterns of microvascular response associated with reflex sympathetic dystrophy of the hand and wrist// J.Hand Surg.-1993.- V.18A, N5.- P.847-852. 25. Sudeck P.: Ueber die akuteenzundicheKnochenatrophie. Arch. klin. Chir. 62:147, 1900.

26. Steinbrocker O.: The shoulder-hand syndrome. Am. J. Med. 3:402, 1947.

27. Travell J. G., Simons D. G. Myofascial Pain and dysfunction. The triggerpoint manual. Baltimore London: Williams and Wilkins 1983. 
XÜLASə

\title{
KOMPLEKS REGIONAR AĞRI SINDROMU - REGIOONAR SKELET-ӘZӘLӘ AĞRISI
}

\author{
İvaniçev Q.A.
}

Kazan Dövlət Tibb Akademiyası, Kazan

Yuxarı ətrafinın kompleks regionar ağrı sindromu (Zudek sindromu) tipik patoloji prosess kimi qiymətləndirilir. $\mathrm{Bu}$ sindromun əsasını tərkibində çoxlu sayda simpatik lifləri olan orta sinirinin irritativ sindromu ilə yanaşı saitin rotatorlarının miofassial ağrı sindromu təşkil edir. 1-ci mərhələ - ulduz qanqlionunun irritasiyasi ilə yanaşı birinci qabırğanın blokadası və eyni zamanda dirsək oynağının blokadası ilə yanaşı saitin rotatorlarının miofassial ağrı sindromunun yaranması. 2-ci mərhələ - saitin yuxarı üçdə birində fibroz-əzələ kanalında orta sinirinin irritasiyası ilə yanaşı reqionar miofassial ağrı sindromu. 3-cü mərhələ - qolun tipik kompleks yuxar1kvadrant veqetativ-irritativ reqionar ağrı sindromunun formalaşmasıın yekunu.

Açar sözləri: regionar ağrı, miofassial ağrı sindromu.

\section{SUMMARY}

\section{COMPLEX REGIONAL PAIN SYNDROME -} REGIONAL SCELETO-MUSCULAR PAIN

\author{
Ivanichev G.A. \\ Kazan State Medical Academy, Kazan
}

\begin{abstract}
Complex regional pain syndrome of hands (the Zudeck`s syndrome) rates as standard pathological process, leading component of which is myofascial pain syndrome of rotators of a forearm with with irritation of the median nerve, containing of big amount of sympathetic filaments. 1 stage - blocking first rib with irritation of stellate ganglion and simultaneously blocking the elbow joint with forming of myofascial pain syndrome of rotators of a forearm. 2 stage - regional myofascial pain syndrome with irritation of the median nerve in upper one third of the forearm in fiber-muscular channel. 3 stage - termination of the development of upper-quadrant vegetativ-irritativ typical complex complex pain syndrome of the hand.
\end{abstract}

Key words: regionar pain, myofascial pain syndrome. 